\title{
A novel neurotherapeutic for multiple sclerosis, ischemic injury, methamphetamine addiction, and traumatic brain injury
}

\author{
Arthur A. Vandenbark ${ }^{1,2,3^{*}}$, Roberto Meza-Romero ${ }^{1,2}$, Gil Benedek ${ }^{4}$ and Halina Offner ${ }^{1,2,5}$
}

\begin{abstract}
Neurovascular, autoimmune, and traumatic injuries of the central nervous system (CNS) all have in common an initial acute inflammatory response mediated by influx across the blood-brain barrier of activated mononuclear cells followed by chronic and often progressive disability. Although some anti-inflammatory therapies can reduce cellular infiltration into the initial lesions, there are essentially no effective treatments for the progressive phase. We here review the successful treatment of animal models for four separate neuroinflammatory and neurodegenerative CNS conditions using a single partial MHC class II construct called DRa1-hMOG-35-55 or its newest iteration, DRa1(L50Q)hMOG-35-55 (DRhQ) that can be administered without a need for class II tissue type matching due to the conserved DRa1 moiety of the drug. These constructs antagonize the cognate TCR and bind with high affinity to their cell-bound CD74 receptor on macrophages and dendritic cells, thereby competitively inhibiting downstream signaling and pro-inflammatory effects of macrophage migration inhibitory factor (MIF) and its homolog, Ddopachrome tautomerase (D-DT=MIF-2) that bind to identical residues of CD74 leading to progressive disease. These effects suggest the existence of a common pathogenic mechanism involving a chemokine-driven influx of activated monocytes into the CNS tissue that can be reversed by parenteral injection of the DRa1-MOG-35-55 constructs that also induce anti-inflammatory macrophages and microglia within the CNS. Due to their ability to block this common pathway, these novel drugs appear to be prime candidates for therapy of a wide range of neuroinflammatory and neurodegenerative CNS conditions.
\end{abstract}

Keywords: Multiple sclerosis, Ischemic injury, Methamphetamine addiction, Traumatic brain injury, Inflammation, Macrophage migration inhibitory factor, Neurotherapy, Partial MHC class II constructs, DRhQ

\section{Introduction}

Trauma, vascular insufficiency, drug abuse, and autoimmune diseases that cause damage to the central nervous system (CNS) may have catastrophic consequences. Unfortunately, there are few effective treatments available that can ameliorate these conditions once the initial damage has occurred. In this review, we introduce a novel neurotherapeutic approach that has shown efficacy for treatment in animal models of acute and chronic multiple sclerosis (MS), ischemic injury including transient and permanent stroke, methamphetamine addiction,

\footnotetext{
*Correspondence: vandenba@ohsu.edu

'Neuroimmunology Research, R\&D-31, VA Portland Health Care System, 3710

SW U.S. Veterans Hospital Rd., Portland, OR 97239, USA

${ }^{2}$ Department of Neurology, Oregon Health \& Science University, 3181 SW

Sam Jackson Park Rd, Portland, OR 97239, USA

Full list of author information is available at the end of the article
}

and traumatic brain injuries by modulating a key neuroinflammatory pathway shared by all of these conditions.

\section{Validation of RTL concept in various rodent models for multiple sclerosis}

Starting in the mid-1990s, our laboratory designed and expressed an extensive set of unique soluble, tunable recombinant protein constructs that mimic the major histocompatibility complex (MHC) class II/peptide interface with a cognate $\mathrm{T}$ cell receptor [1-3]. We designated these constructs as recombinant $\mathrm{T}$ cell receptor ligands (RTLs). The original goal was to regulate the activation and function of selected pathogenic $\mathrm{T}$ cells in an MHC-restricted, antigen-specific manner. To start, we chose the experimental autoimmune encephalomyelitis (EAE) model for which there were a number of 
different combinations of encephalitogenic peptides and their corresponding MHC class II restriction molecules. Our first construct, RTL201, comprised of the covalently linked RT-1B $\beta 1$ and $\alpha 1$ domains from the Lewis rat strain covalently linked to the dominant encephalitogenic guinea pig myelin basic protein (MBP) 69-89 peptide, was found to inhibit activation and proliferation of MBP-69-89-specific T cells and prevent and reverse EAE induction [4, 5]. These studies revealed several key points regarding RTL therapy. First, the combination of both MHC and peptide components of the RTL were required for successful treatment of EAE. Second, RTL treatment of EAE drastically decreased the number of encephalitogenic cells that migrated from the periphery into the CNS. Third, RTL therapy decreased both proliferation and pro-inflammatory cytokine responses of cultured MBP-specific lymph node $\mathrm{T}$ cells, strongly suggesting direct modulation of encephalitogenic $\mathrm{T}$ cells. Finally, we demonstrated direct binding of RTL201 to a soluble single-chain $\mathrm{T}$ cell receptor (TCR) from an encephalitogenic MBP-69-89-specific $\mathrm{T}$ cell clone using surface plasmon resonance, thereby proving selective RTL targeting of its cognate TCR [6].

This first success of the concept led to many more constructs for treatment of EAE as well as other inflammatory conditions. For $\mathrm{SJL} / \mathrm{J}$ mice, we produced I- $\mathrm{A}^{\mathrm{s}} \beta 1$ and $\alpha 1$ domains linked to proteolipid protein (PLP)-139-151 (RTL401), PLP-178-191 (RTL402), or myelin basic protein (MBP)-84-104 peptide (RTL403) that could treat relapsing EAE induced by whole spinal cord homogenates as well as by the respective encephalitogenic peptides [7, 8]. Moreover, we found that SJL/J mice immunized with multiple encephalitogenic peptides could be treated with single RTLs targeting any of the contributing pathogenic $\mathrm{T}$ cells, indicating a bystander suppression effect that was eventually determined to be mediated through a cytokine switch involving upregulation and secretion of IL-10 and IL-13 [7-9]. Finally, RTL401 was found to be highly effective in promoting repair of myelin and axonal damage in chronic EAE [10].

For C57BL/6 mice, we designed RTL551 (I-A ${ }^{\mathrm{b}} \beta 1$ and $\alpha 1$ domains linked to mouse (m)MOG-35-55 peptide), which were highly effective for treating acute and chronic EAE induced by active immunization with mouse (m)MOG-35-55 peptide or passive EAE induced after transfer of MOG-specific T cell lines [11]. We thus demonstrated that RTL551 treatment could selectively reduce secretion of IL-17 and tumor necrosis factor (TNF) $\alpha$ and expression of many chemokines and chemokine receptors by transferred green fluorescent protein (GFP)-labeled encephalitogenic $\mathrm{T}$ cells, resulting in a dissolution of existing cellular lesions in spinal cords. Of key importance, RTL551 downregulated expression of VCAM-1 and ICAM- 1 by vascular endothelial cells of the blood-brain barrier. These studies demonstrated the importance of RTL therapy for blocking migration of encephalitogenic T cells into the CNS and removal of existing inflammatory cells within spinal cord lesions.

Partial (p)MHC constructs containing DR $\beta 1 * 1501$ and $\mathrm{DR} \alpha 1$ domains linked to human (h) or (m)mouse MOG-35-55 peptides or to MBP-85-99 peptide were also designed for studies using human $\mathrm{T}$ cells $[12,13]$ and for treatment of EAE in humanized transgenic DR2 "1501 and "1502 class II expressing mice [14, 15]. In each set of studies, these various MHC-matched RTL constructs were found to prevent or reverse clinical and histological severity of EAE mediated by the targeted T cell specificity [15-17]. In contrast, no modulation of EAE was observed using control RTLs comprised of a matched or mismatched MHC class II $\beta 1 / \alpha 1$ moiety linked to non-cognate encephalitogenic peptides or to non-encephalitogenic peptides, thus confirming selective $\mathrm{T}$ cell targeting.

\section{RTL signaling through the T cell receptor}

To evaluate RTL signaling through the TCR, we used RTL201 to activate the A1 T cell hybridoma specific for MBP-72-89. Incubation with RTL induced a partial activation that included a $\mathrm{CD} 3 \zeta \mathrm{p} 23 / \mathrm{p} 21$ ratio shift, ZAP-70 phosphorylation, internal calcium mobilization, NFAT activation, and transient IL-2 production [18]. In comparison, incubation of the A1 hybridoma cells with $\alpha-C D 3 \varepsilon$ produced full activation of these cellular events, with pronounced external and internal calcium mobilization, activation of NFKB and extracellular-regulated kinase (ERK), as well as long-term increased IL-2 production. These results demonstrate that RTLs can induce signaling directly through the TCR to deplete intracellular calcium stores without fully activating the $\mathrm{T}$ cells. The resulting Ag-specific partial activation of the transcription factor NFAT uncoupled from the activation of NFkB or ERKs constitutes a unique downstream activation pattern that can account for the inhibitory RTL effects on encephalitogenic $\mathrm{CD} 4^{+} \mathrm{T}$ cells.

These findings were corroborated and extended using RTL303 (DR2 $\beta 1 \alpha 1-M B P-72-89)$ to inhibit activation of an MBP-85-99-specific, DR2-restricted human $\mathrm{T}$ cell clone [5]. Incubation with RTL again induced a partial activation characterized by rapid TCR $\zeta$-chain phosphorylation, calcium mobilization, and reduced extracellular signal-related kinase activity, as well as IL-10 production, but did not induce proliferation, Th1 cytokine response, or IL-2R $\alpha$ expression. Upon restimulation with antigen-presenting cells (APC) primed with the MBP-85-99 peptide, the RTL-pretreated Th1 clones had reduced proliferation and IFN- $\gamma$ secretion, but continued IL-10 secretion and a normal expression level of IL-2R $\alpha$. 
Antigen-specific IL-10 secretion by Th1 clones in response to RTL treatment confirms a "cytokine shift" to IL-10 that can account for "bystander suppression" as was seen in rodents that continued even after restimulation of the RTL-pretreated clones with APC/Ag.

\section{Clinical trial with RTL1000}

In 2007-2009, we carried out a phase 1 double-blind, placebo-controlled, single-ascending dose clinical trial that involved 34 relapsing-remitting and secondary progressive male and female MS individuals, each receiving RTL1000 (DR2 $\beta 1 \alpha 1-h M O G-35-55)$ or vehicle $[19,20]$. The trial design involved 6 cohorts (randomized 4:2 to receive i.v. doses of $2,6,20,60,100$, or $200 \mathrm{mg}$ drug vs. vehicle). The primary objective was to evaluate the safety profile of RTL1000, and the secondary objectives were to evaluate its $\mathrm{PK}$ profile and immunological parameters in a subset of participants. The results of this trial established that RTL1000 was safe (no exacerbations or increased MRI lesions or severe adverse events; no significant induction of anti-drug antibodies) and well tolerated at a dose of $\leq 60 \mathrm{mg}$, with a half-life of $<10 \mathrm{~min}$.

\section{Discovery of the RTL receptor, CD74, and the involvement of MIF}

We determined that RTLs bind predominantly to the cell surface of monocytes, dendritic cells, and B cells in vitro [21] in a saturable manner, thus accounting for rapid partitioning from plasma to the cellular compartment (half-life $<10 \mathrm{~min}$ ) [20]. Moreover, RTL binding to mouse APCs inhibited $\mathrm{T}$ cell activation and passive transfer of clinical and histological signs of EAE [21]. Taken together, these findings suggested a cell-associated RTL receptor which initiates peptide-dependent $\mathrm{T}$ cell tolerance involving cell-cell interactions beyond simple ligation of the TCR by soluble RTLs. RTL receptors therefore may be important for maintaining homeostasis and inducing $\mathrm{T}$ cell tolerance.

Further studies revealed that RTLs bind tightly to a molecular complex comprised of CD74, surface histones, and MHC class II itself [17]. This complex was expressed predominantly on $\mathrm{CD}_{11 \mathrm{~b}^{+}}$monocytes and was required for treatment of EAE with a mouse version of RTL1000. RTL constructs with or without tethered antigenic peptide rapidly downregulated CD74 in a dose-dependent hierarchical manner, and blocked signaling of the inflammatory cytokine, macrophage migration inhibitory factor (MIF), and its homolog, D-dopachrome tautomerase (D-DT), for which CD74 serves as the cognate receptor. Furthermore, a significant structure activity relationship (SAR) was established between RTL-modulated CD74 levels on $\mathrm{CD}_{11 \mathrm{~b}^{+}} \mathrm{CNS}$ cells and clinical severity of EAE. These results demonstrate that
RTL constructs trigger both peptide-dependent and peptide-independent regulatory pathways that contribute to $\mathrm{T}$ cell tolerance and EAE treatment effects.

\section{Discovery and development of DRa1 constructs}

With the focus on CD74 as the major receptor for two-domain partial (p)MHC class II constructs, we discovered that only the $\alpha 1$ domain but not the $\beta 1$ domain could bind to immune-precipitated CD74 [17]. This led to the demonstration that the MHC class II DR $\alpha 1$ domain alone retains the inhibitory activity of the pMHC constructs for MIF and D-DT binding and signaling [22]. These activities of the recombinant DR $\alpha 1$ domain could be destroyed by trypsin digestion but were enhanced nearly 50 -fold by covalently linking the MOG-35-55 peptide to the $\mathrm{N}$-terminus of DR $\alpha 1$. This new construct exhibited discrete secondary $\alpha$-helical and $\beta$-sheet structure as assessed by circular dichroism that was similar to secondary structure observed in the two domain pMHC. These data suggested a conformational determinant on DR $\alpha 1-M O G-35-55$ that is responsible for optimal binding to CD74 and antagonism of MIF effects, resulting in reversal of clinical and histological signs of EAE. Moreover, because the DR 11 domain as well as the MOG-35-55 moiety are present and invariable in all humans, this construct should not be recognized as foreign and treatment using this DR $\alpha 1$ construct would not require HLA matching in potential recipients. This feature of DR 1 -MOG-35-55 construct is a substantial improvement over the initial RTL1000 construct that would allow immediate treatment for acute brain injuries such as TBI and stroke.

\section{Treatment of acute and chronic EAE with DRa1-MOG-35- 55 constructs}

Multiple sclerosis (MS) is a devastating demyelinating neurological disease with an autoimmune origin involving both genetic and environmental factors in disease pathogenesis [23, 24]. Encephalitogenic T cells, macrophages, and microglia play a central role in multiple sclerosis and EAE pathology with $\mathrm{T}$ cells and macrophages, migrating across the blood-brain barrier and orchestrating a proinflammatory attack that causes myelin damage and neuronal death leading to the progression of disease severity [23, 25-27]. As discussed above, MIF and D-DT are key cytokines thought to drive the early inflammatory stage of MS to a chronic progressive phase. MIF and DDT levels and have been implicated as markers of clinical worsening in MS and as a requirement for disease progression in EAE. The RTL constructs bind tightly to the MIF/DDT receptor, CD74, and competitively inhibit MIF/DDT binding and downstream signaling through phosphorylated (p)ERK1/2. 
Due to the ability of our second generation DR $\alpha$ 1-MOG-35-55 construct (see sequence and ribbon structure in Fig. 1a) to retain the immunoregulatory activity of the RTL1000 construct, we are now focused on testing DR $\alpha 1-M O G-35-55$ effects on treatment of EAE, with the intent of developing it for use in FDA approved clinical trials in MS and other CNS conditions.

\section{DRa1-mMOG-35-55 treatment reverses clinical signs of EAE}

As described above, we demonstrated that DR $\alpha 1-m M O G-35-55$ treatment could reverse clinical signs of EAE in DR $\alpha 1$-matched HLA-transgenic $\mathrm{DR}^{*} 1501$ mice [22]. We then wished to test if the DR 1 1-mMOG-35-55 construct could treat EAE in mice that expressed mouse I-A/I-E genes, as opposed to the human HLA-DR $\alpha 1$ and DR2 $\beta 1$ domains expressed in the DR*1501-Tg mice. Indeed, treatment of C57BL/6 mice immunized with mouse (m)MOG-35-55/CFA/Ptx $(100 \mu \mathrm{g}$ daily $\times 5)$ after disease onset significantly reduced clinical and histological signs of EAE compared with vehicle-treated mice (Fig. 1b, c) [28]. These results indicate that DR $\alpha 1-\mathrm{mMOG}-35-55$ is a potent therapeutic agent to treat EAE in mouse strains expressing different $\mathrm{MHC}$ gene sequences but the same disease-inducing mMOG-35-55 peptide.

\section{DRa1-mMOG-35-55 treatment reduces the number of CNS- infiltrating cells and their activation state}

In order to evaluate effects of DR $\alpha 1-m M O G-35-55$ treatment on migration of activated immune cells into the CNS, mononuclear cells were isolated from brains and spinal cords from C57BL/6 mice 5 days post-EAE treatment. The absolute number of mononuclear cells was reduced both in the brain and spinal cord of DR $\alpha$-mMOG-35-55-treated vs. vehicle-treated mice with EAE (Fig. 1d) [28]. This reduction was reflected in the absolute number of infiltrating monocytes and activated resident microglia $\left(\mathrm{CD} 11 \mathrm{~b}^{+} \mathrm{CD} 45^{\mathrm{hi}}\right)$ as well as $\mathrm{CD}^{+} \mathrm{T}$ cells in the spinal cord $(p<0.05$; Fig. $1 \mathrm{~d})$. In addition, the CD74 expression level on $\mathrm{CD}_{11} \mathrm{~b}^{+} \mathrm{CD} 45^{\text {hi }}$ cells was significantly lower in the spinal cords of DR $\alpha 1$-mMOG-35-55- vs. vehicle-treated mice $(p<0.05$; Fig. 1d), in accordance with effects of the parent DR*1501 $\beta 1 \alpha 1$-mMOG-35-55 RTL construct in DR*1501-Tg mice [15]. Furthermore, there was a significantly lower frequency of PMA/ionomycin-stimulated IL- $17^{+} \mathrm{T}$ cells but not $\mathrm{CD}^{+}{ }^{+} \mathrm{IFN}_{-} \gamma^{+} \mathrm{T}$ cells from DR 1 1-mMOG-35-55-treated mice compared with stimulated cells from vehicle-treated mice $(p<0.05$; Fig. 1d). Collectively, these data suggest that DR $\alpha 1-m M O G-35-55$ inhibits migration of activated inflammatory cells from the periphery to the CNS of C57BL/6 mice and that the infiltrating cells in the spinal cords of DR $\alpha 1-$ mMOG-35-55-treated mice have reduced expression of CD74 and are less inflammatory compared with spinal cord cells from vehicle-treated mice.

\section{DRa1-mMOG-35-55 treatment enhances the frequency of $C D 11 b^{+} C D 206^{+}$anti-inflammatory macrophages in spinal cords of mice with $E A E$}

During EAE, proinflammatory macrophages have been shown to induce CNS inflammation, whereas anti-inflammatory macrophages were shown to be involved in neuroprotection and remyelination [29-31]. We analyzed the frequency of activated $\mathrm{CD} 11 \mathrm{~b}^{+} \mathrm{CD} 206^{+}$ M2-like macrophages in spinal cords of C57BL/6 mice with EAE $24 \mathrm{~h}$ after the last treatment with DR 1 -mMOG-35-55 or vehicle. As shown in Fig. 1d, the frequency of M2-like macrophages $\left(\mathrm{CD} 11 \mathrm{~b}^{+} \mathrm{CD} 206^{+}\right)$was significantly increased in DR $\alpha 1-\mathrm{mMOG}-35-55$-treated vs. vehicle-treated mice $(p<<0.05)$. In contrast, no

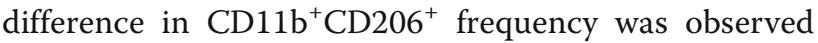
in the periphery [28].

In order to determine whether DR $\alpha 1-m M O G-35-55$ could directly induce M2-like polarization, we isolated spleen cells from untreated C57BL/6 mice with EAE on day 15 post-immunization and stimulated them with LPS, LPS/MIF, LPS/MIF/DR $\alpha 1-\mathrm{mMOG-35-55,} \mathrm{or}$ DR $\alpha 1-m M O G-35-55$ alone for $24 \mathrm{~h}$ at $37^{\circ} \mathrm{C}$. As expected, LPS or LPS/MIF treatment reduced the anti-inflammatory $\mathrm{CD} 11 \mathrm{~b}^{+} \mathrm{CD} 206^{+}$frequency by $\sim 80 \%$ $(p<0.001)$. Treatment with LPS/MIF + DR 1 1-mMOG-35-55 or DR 1 -mMOG-35-55 alone significantly increased the frequency of

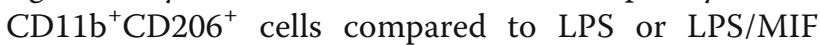
treatment $(p<0.001)$, but only to $\sim 40 \%$ of control levels. Similar effects were observed in DR*1501-Tg mice (not shown). Taken together, we conclude that DR $\alpha 1-m M O G-35-55$ treatment mainly inhibits the effects of a pro-inflammatory milieu on M1-like polarization but apparently does not directly induce M2-like polarization [28].

\section{DRa1-mMOG-35-55 treatment of EAE reduces the expression of pro-inflammatory genes and increases the expression of genes involved in neurosurvival and regeneration}

To evaluate DR $\alpha 1$-mMOG-35-55 effects on CNS inflammation during EAE in a more comprehensive manner, we performed microarray analysis on spinal cords from DRo1-mMOG-35-55- vs. vehicle-treated DR*1501-Tg mice with EAE. EAE was induced with mMOG-35-55/ CFA/Ptx, and mice were treated with DR $\alpha 1-m M O G-35-55(100 \mu$ g daily $\times 3)$ or vehicle after disease onset at a clinical score of 2 . Twenty-four hours after the last treatment, total RNA was isolated from spinal cords and gene expression profiles from pooled RNA were analyzed using the Mouse Gene 2.0 ST 


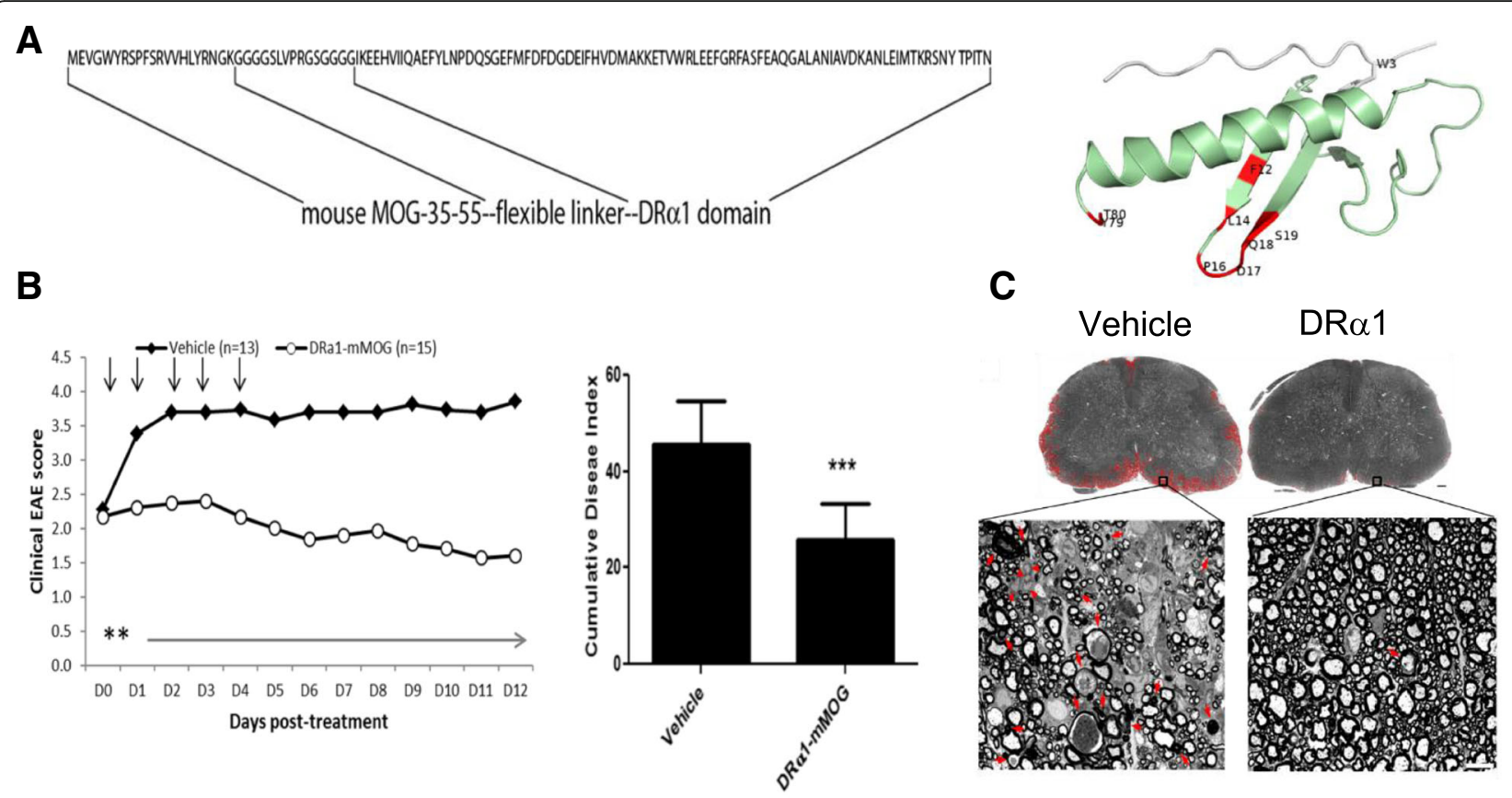

D
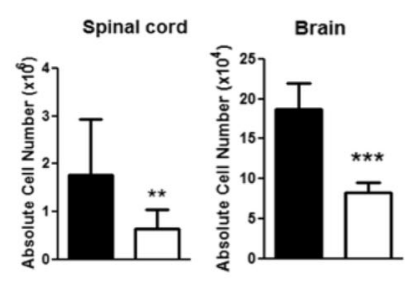
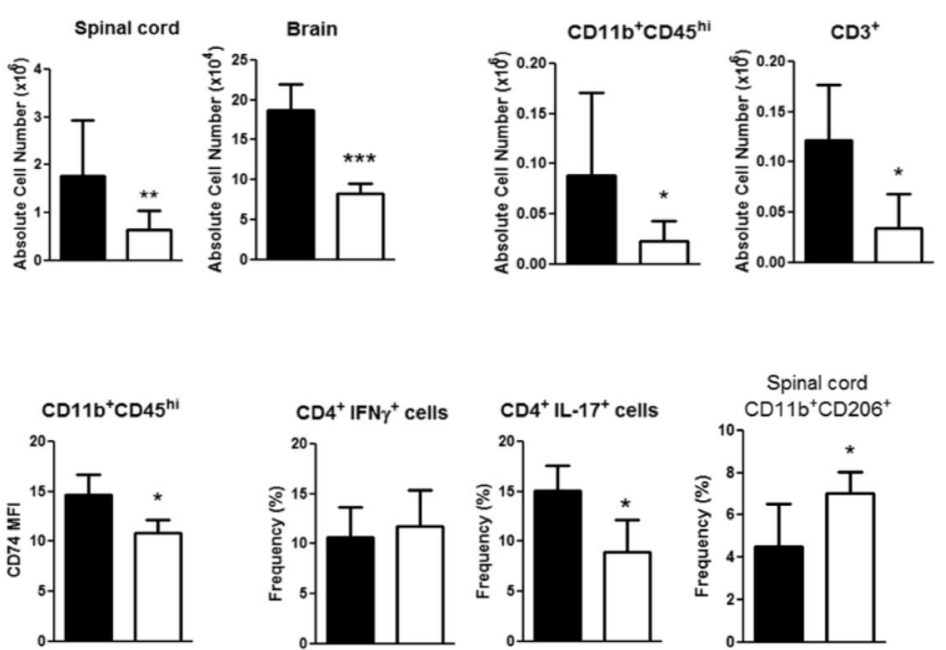

E
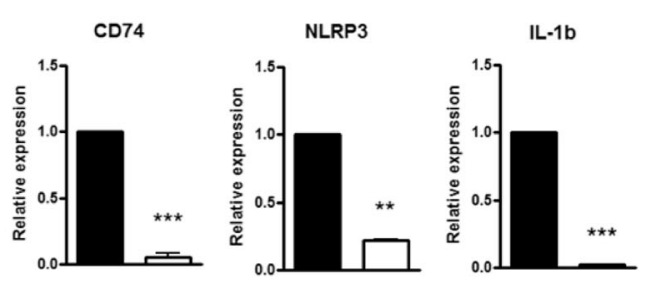

Fig. 1 Design and treatment effects of the DRa1-mMOG-35-55 construct in acute EAE: a Design, sequence and ribbon model of the DRa1-

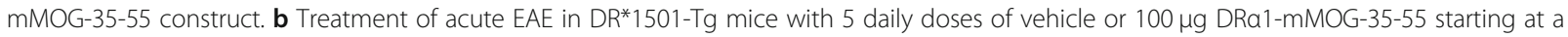
score of $\geq 2$ reduced daily $\left({ }^{* *} p<0.01\right)$ and cumulative $\left({ }^{* *} p<0.001\right)$ disease scores and $\mathbf{c}$ spinal cord histological damage (red) and demyelination as visualized after toluidine blue staining (scale bar $100 \mathrm{~mm}$ ). High-power view of small areas of lumbar spinal cord (black rectangles) show axons that are undergoing demyelination (red arrow) and cellular infiltration (red arrowhead). Scale bar is $10 \mathrm{~mm}$. d DRa1-mMOG-35-55 treatment of C57BL/6 male mice with EAE reduced the absolute numbers of lymphocytes, CD $11 b^{+} C D 45^{\text {high }}$ myeloid cells, and $\mathrm{CD} 3^{+} \mathrm{T}$ cells in the spinal cord and brain, expression of CD74 on CD11 $\mathrm{b}^{+} \mathrm{CD} 45^{\text {high }}$ spinal cord cells and intracellular expression of $\mathrm{CD} 4^{+} \mathrm{IL}-17^{+} \mathrm{T}$ cells in the brain (after stimulation with PMA and ionomycin) and increased the frequency of CD206 ${ }^{+} \mathrm{CD} 11 \mathrm{~b}^{+} \mathrm{CD} 45^{\text {hi }}$ cells in spinal cords. e DRa1-mMOG-35-55 treatment reduced the relative expression of pro-inflammatory genes (CD74, NLRP3, and IL-1b) and increased the expression of genes involved in neurosurvival and regeneration (HUWE1, MBP, and HDAC5) in spinal cord samples from C57BL/6 male mice. ${ }^{*} p<0.05,{ }^{* *} p<0.01,{ }^{* * *} p<0.001$. Panels (a) (partial), (b, d, and e) reprinted [adapted] from "HLA-DRa1-mMOG-35-55 treatment of Experimental autoimmune encephalomyelitis reduces CNS inflammation, enhances M2 macrophage frequency, and promotes neuroprotection," by Benedek et al., 2015, Journal of Neuroinflammation, 12:123, Biomedical Central, copyright Benedek et al. 2015 [28]. Reprinted with permission. Published with original ribbon graphic of the DRa1-MOG-35-55 construct. Panel (c) reprinted from "HLA-DRa1 constructs block CD74 expression and MIF effects in experimental autoimmune encephalomyelitis," by Meza-Romero et al., 2014 [22]. Journal of Immunology, 192(9):4164-73, copyright of The American Association of Immunologists. Reprinted with permission 
Affymetrix GeneChip system. Relative up- or downregulated genes after treatment with DR $\alpha 1$-mMOG-35-55 plotted against their expression level in spinal cords of vehicle-treated mice revealed 1049 probes that were downregulated by twofold or greater. Out of these probes, 160 genes were shown to be involved in inflammation processes. Conversely, 568 probes were upregulated by twofold or greater in the spinal cord of DR $\alpha 1$-mMOG-35-55-treated vs. vehicle-treated mice. Gene ontology analysis of the genes that were upregulated did not reveal a distinct pathway as was observed for downregulated pro-inflammatory response genes. However, several of the genes that were relatively upregulated by DR $\alpha 1-m M O G-35-55$ treatment were shown to be involved in neuroregeneration, including Prosaposin (PSAP), Myocilin (MYOC), E3 ubiquitin ligase Huwe1, and 3-phosphoinositide-dependent protein kinase 1 (PDPK-1) [32-37]. We validated these microarray results by real-time PCR analysis of spinal cord mRNA from three individual mice in each group (Fig. 1e). Indeed, pro-inflammatory genes such as CD74, Nlrp3, and IL-1b were significantly downregulated in spinal cords of DR $\alpha 1$-mMOG-35-55-treated vs. vehicle-treated mice ( $p$ $<0.001, p<0.01$, and $p<0.001$, respectively), whereas Huwe1 and MBP were significantly upregulated $(p<$ 0.05 ). Histone deacetylase 5 (HDAC5) was also upregulated, although results did not reach significance [38, 39]. These results indicate the CNS of DR $\alpha 1$-mMOG-35-55-treated mice is not only less inflammatory but also that this treatment could inhibit and potentially reverse ongoing demyelination and neurodegeneration [28].

\section{Sex-dependent efficacy of DRa1-mMOG-35-55 in treating chronic EAE}

As shown above, we demonstrated that our second generation pMHC construct, DR $\alpha$-mMOG-35-55, could successfully treat EAE when injected into either HLA "matched" DR2-Tg mice or "mismatched" C57BL/6 mice at a clinical score of $\geq 2[2,22]$. We thus tested the ability of DR $\alpha 1-m M O G-35-55$ to treat chronic EAE in "mismatched" C57BL/6 mice and found an unexpected sex-dependent pattern of treatment, with the 100- $\mu \mathrm{g}$ dose producing a significant improvement of chronic EAE in males (Fig. 2a; $p<0.05$ ) but not females (Fig. 2b) [40]. These data were reminiscent of the same sex-dependent response to treatment in experimental stroke (shown below), but in that case, females unresponsive to the $100-\mu \mathrm{g}$ dose could be effectively treated with a 10-fold higher 1000- $\mu$ g dose of DR $\alpha 1$-mMOG-35-55 [41]. As demonstrated for the DR*1501-Tg mice, there were no statistical differences in the disease course or the CDI between vehicle-treated male and female $\mathrm{C} 57 \mathrm{BL} / 6$ mice. Thus, we repeated the experiment in female C57BL/6 mice with chronic EAE using the 1-mg dose of DR $\alpha$-mMOG-35-55 and found a marked early and significant cumulative treatment effect similar to the low-dose treatments in male mice (Fig. 2b; $p<0.05$ ). Analysis of spinal cords from DR $\alpha 1-m M O G-35-55$-treated female mice revealed nominally less axonal damage compared to vehicle-treated mice $(2.6 \pm 0.6 \%$ vs. $5.2 \pm 1.2 \%$, respectively; Fig. 2d), significantly less demyelination $(2.1 \pm 0.3 \%$ vs. $11.2 \pm 2.3 \%$, respectively, $p<0.01$; Fig. 2e), and reduced inflammation marked by significantly reduced frequencies of $\mathrm{CD} 11 \mathrm{~b}^{+}(1.6 \pm 0.1 \%$ vs $3.6 \pm 0.5 \%$, respectively, $p<0.05)$ and $\mathrm{CD}^{+} \mathrm{T}$ cells $(0.16 \pm 0.04 \%$ vs $0.6 \pm 0.14 \%$, respectively, $p<0.05)$ (Fig. 2f). These results suggested that the difference in effective dose for treatment of chronic EAE with DR $\alpha 1-m M O G-35-55$ is sex dependent.

\section{DRa1-mMOG-35-55 treatment efficacy of female mice depends on estrogen signaling through ERa}

Sex hormones have been shown to both positively and negatively regulate the immune system [21, 42, 43]. In order to evaluate the effect of female sex hormones on the treatment response in chronic EAE, WT and ovariectomized (OVX) C57BL/6 female mice were treated with $100 \mu$ g DR $\alpha 1-m M O G-35-55$. Unlike the lack of treatment effect in WT C57BL/6 female mice shown above, there was a significant treatment effect with this lower $100-\mu \mathrm{g}$ dose in OVX females $(p<0.05$, not shown). To evaluate a specific role for estrogen in regulating the effective dose of RTL constructs, estrogen receptor (ER) $\alpha$ and ER $\beta$ knockout (ERKO and BERKO, respectively) mice were treated on day 20 post immunization with $100 \mu \mathrm{g}$ DR $\alpha 1-\mathrm{mMOG}-35-55$, with boosting for 3 days starting on days 35 and 49 post-injection as before. DR $\alpha 1-m M O G-35-55$ treatment significantly reduced disease severity in ERKO (Fig. 2c) but not BERKO (not shown) female mice compared to vehicle-treated mice [40]. Taken together, these data clearly demonstrate that estrogen signaling through ER $\alpha$ affects the potency of partial MHC class II constructs to treat chronic EAE.

\section{Ischemic injury models of stroke Middle cerebral artery occlusion (MCAO)}

Ischemic CNS injury triggering stroke is a leading cause of death and disability worldwide $[44,45]$, and it is anticipated that nearly $4 \%$ of the US population will sustain a stroke by 2030 [46]. Inflammation involving rapid activation of microglia and time-dependent infiltration of activated peripheral immune cells, including neutrophils, macrophages, $\mathrm{T}$ cells, and $\mathrm{B}$ cells, into the affected brain tissue is a major contributor to onset and progression of stroke [47-52]. In MCAO, the initial influx of inflammatory cells is followed by a profound degree of immunosuppression marked by atrophy of the spleen and 


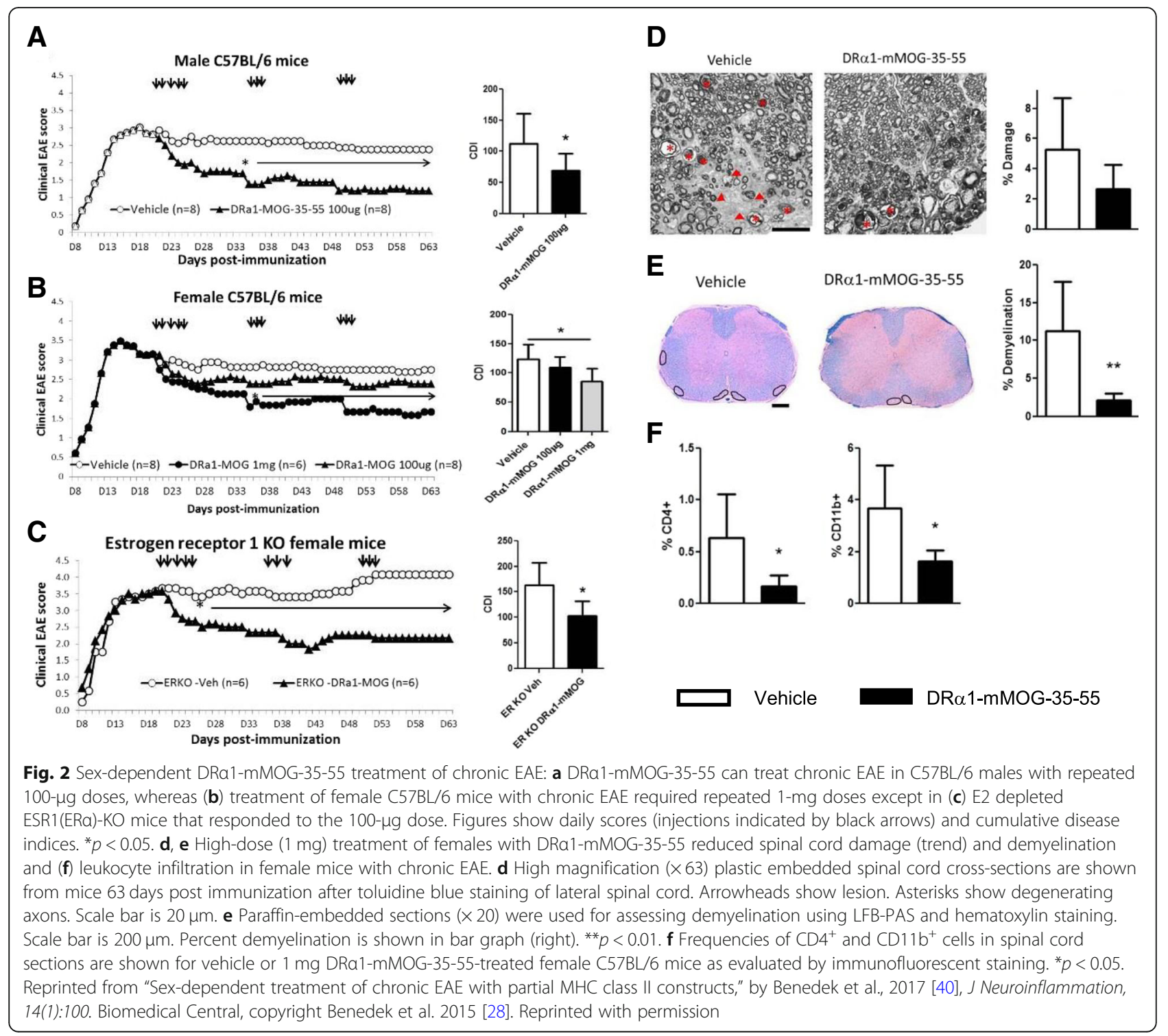

thymus [50, 53-55]. While pro-inflammatory immunocytes, including MOG-35-55-specific T cells [56], exacerbate stroke, alternatively activated macrophages and microglia provide a critical balance for regulating inflammation and tissue repair $[31,57]$.

Currently, tissue plasminogen activator (tPA) remains the only FDA-approved drug for ischemic stroke, and there is a crucial unmet need for new drugs that meet the Stroke Academic Industry Roundtable (STAIR) criteria. According to these criteria, an optimal therapy should exhibit the following characteristics: (1) efficacy in aged animals and animals with co-morbidity, (2) efficacy in both male and female animals, (3) compatible interaction with tPA, (4) biomarker endpoints (MRI, serum markers), and (5) reproducibility in at least one independent laboratory [58]. As reviewed previously, our RTL constructs have been shown to reduce infarct volume and neurological deficit in various cerebral ischemia models in young adult and aging male and female mice. In addition, partial MHC class II constructs were shown to reverse stroke-associated splenic atrophy and promote a protective anti-inflammatory macrophage/microglia phenotype in the CNS which contributes to tissue repair and recovery after stroke [59, 60]. A recent study has also demonstrated increased expression of CD74 on T cells and antigen-presenting cells that directly correlate with infarct size and neurological deficits in people with ischemic stroke [61].

DRa1-mMOG-35-55 treatment significantly reduces infarct size after MCAO in DR2-Tg mice Evaluation of brain infarcts $96 \mathrm{~h}$ after MCAO demonstrated that DR 1 -mMOG-35-55-treated male DR2-Tg mice had significantly reduced infarct volumes compared with the 
vehicle-treated group as shown in Fig. 3a [62]. Cortical infarct volume was $25.9 \pm 4.67 \%$ in DR 1 -mMOG35-55treated compared to $47.0 \pm 2.5 \%$ in vehicle-treated mice $(p<0.01)$. Similarly, striatal infarct volume was $40.8 \pm 5.4 \%$ vs. $\quad 64.5 \pm 2.0 \%$ respectively in DR $\alpha$-mMOG-35-55-treated vs. vehicle-treated mice $(p<0.01)$, whereas the total hemispheric infarct volume was $19.4 \pm 3.6 \%$ vs. $31.1 \pm 1.71 \%$, respectively $(p<0.01)$. Quantitative assay of TTC stained cerebral sections after $96 \mathrm{~h}$ of reperfusion illustrated the smaller infarct area in DR 1 -mMOG-35-55-treated mice compared with vehicle-treated mice (Fig. 3b). There were no significant differences in laser-Doppler perfusion before, during, or immediately after MCAO between DR 1 1-MOG-35-55reated and vehicle-treated groups.

DRa1-mMOG-35-55 reduces infarct volumes in a dose-dependent manner in female mice Similar to the requirement for higher drug doses for treating female mice during chronic EAE shown above, treatment with $1 \mathrm{mg}$ DR $\alpha 1-\mathrm{mMOG}-35-55$ in DR*1501 female mice also significantly reduced infarct volume relative to vehicle treatment, as shown in Fig. 3c [63]. Cortical volume was $34.9 \pm 7.3 \%$ in DR $\alpha 1$-mMOG-35-55-treated vs. $56.5 \pm 2.9 \%$ in vehicle-treated mice $(p=0.007)$; for striatum, volumes were $48.2 \pm 8.0 \%$ vs. $69.7 \pm 3.7 \%$, respectively $(p=0.02)$; and for hemisphere, volumes were $22.8 \pm 4.4 \%$ vs. $33.1 \pm 1.3 \%$, respectively $(p=0.02)$. In contrast to treatments with two domain RTL1000, 100- $\mu \mathrm{g}$ and 500- $\mu \mathrm{g}$ doses of DR $\alpha 1-\mathrm{mMOG}-35-55 \mathrm{did}$ not significantly improve infarct volumes relative to the vehicle-treated group. No differences were observed in intra-ischemic LDF or temporalis muscle temperature among the various groups, nor were there any differences in body weight, health scores, or mortality rates.

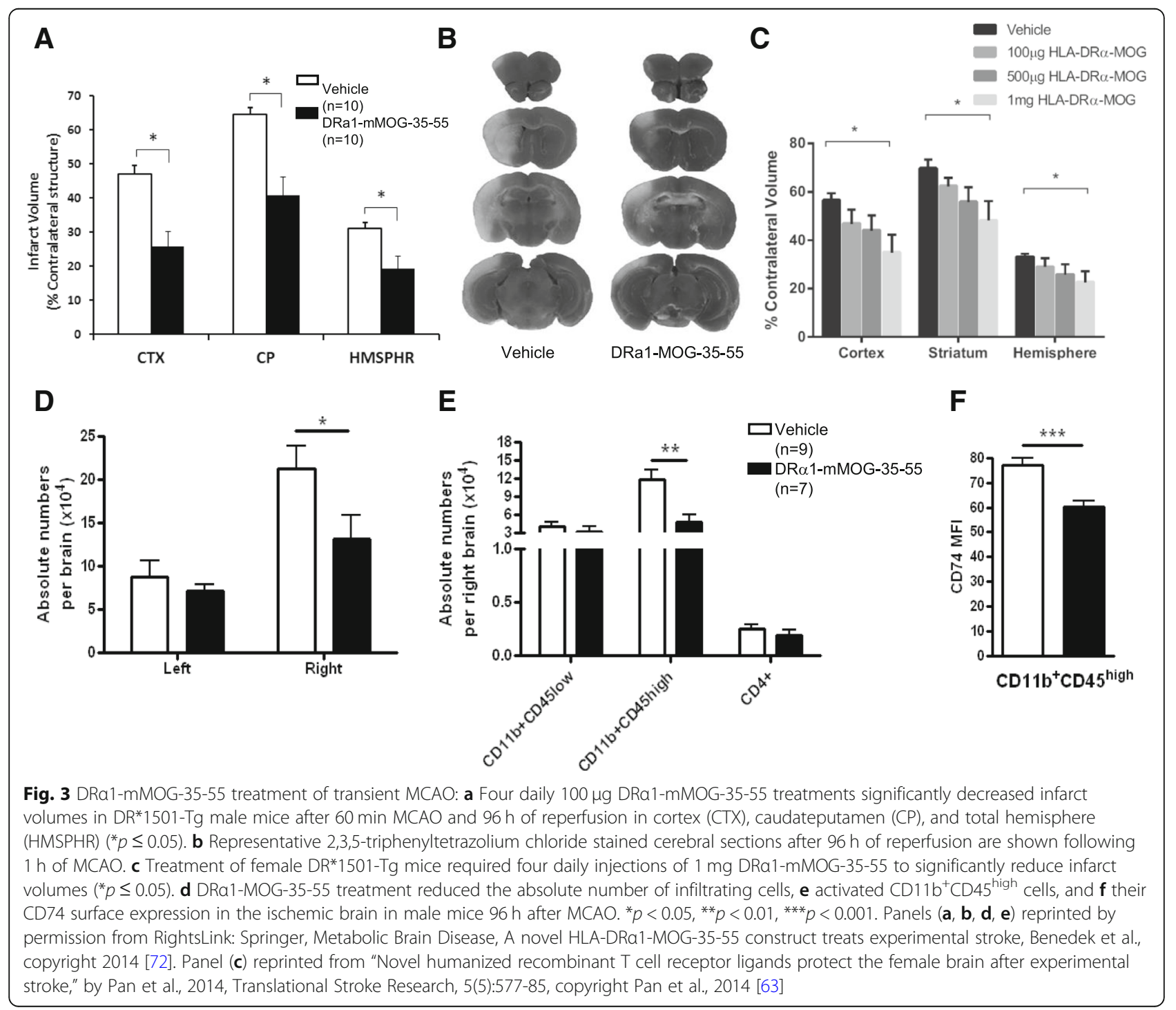


DRa1-mMOG-35-55 reduces the number of activated microglia and infiltrating monocytes and their CD74 cell surface expression in the ischemic brain We sought to determine if the reduced infarct size after DR 1-MOG-35-55 treatment was due to diminished number of infiltrating inflammatory cells in the brain after MCAO. DR $\alpha$-mMOG-35-55 treatment significantly reduced the absolute number of mononuclear cells in the right ischemic brain compared with vehicle-treated mice $(p<0.05)$ (Fig. 3d) [62]. This difference is attributed mainly to the reduction in the number of activated $\mathrm{CD} 11 \mathrm{~b}^{+} \mathrm{CD} 45^{\text {high }}$ monocytes $(p<0.01$; Fig. 3e). There were no significant differences in the absolute numbers of $\mathrm{CD} 4^{+} \mathrm{T}$ cells or resting microglia $\left(\mathrm{CD} 11 \mathrm{~b}^{+} \mathrm{CD} 45^{\text {low }}\right)$. In the non-ischemic left brain, there were no differences in the total absolute number of mononuclear cells or in any specific cell type.

As shown above, we demonstrated that DR $\alpha$ 1-mMOG-35-55 treatment of EAE led to a reduction of activated $\mathrm{CD} 11 \mathrm{~b}^{+}$cells in the spinal cord and that DR $\alpha 1-m M O G-35-55$ reduced the cell surface expression of the MIF receptor, CD74, on the activated $\mathrm{CD}_{11 \mathrm{~b}^{+}}$cells. In order to determine if DR $\alpha 1-m M O G-35-55$ treatment had the same effect in MCAO, expression of CD74 cell surface levels was evaluated on $\mathrm{CD} 11 \mathrm{~b}^{+} \mathrm{CD} 45^{\text {high }}$ cells in the right ischemic hemisphere. As shown in Fig. 3f, there was a significant reduction in the level of CD74 MFI expression in the DR 1 1-mMOG-35-55-treated mice compared with the vehicle-treated mice $(p<0.01)$. Thus, as in EAE, DR 1-mMOG-35-55 can reduce the number of activated microglia and infiltrating monocytes in the ischemic brain and reduce the expression of $\mathrm{CD} 74$ on the surface of these cells.

DRo1-mMOG-35-55 treatment affects the immune gene expression profile in the ischemic brain after MCAO In order to assess the DR $\alpha 1-$ mMOG-35-55 treatment effect on the expression of immune-related genes in brain, mRNA was isolated from the ischemic brains of 3 vehicle-treated mice and 3 DR $\alpha 1-m M O G-35-55$-treated mice. A real-time PCR assay was performed on pooled cDNA samples, and expression levels of the DR $\alpha 1$-mMOG-35-55-treated sample were analyzed relative to the vehicle-treated sample. Validation of 3 genes, IL-4, CCL3, and ACE using individual samples, demonstrated that the expression trends were the same as in the immune array (not shown). The immune array data demonstrated that there was a decrease in the expression of monocyte-related genes such as CCL3 and CCL2 and increase in Th1 and Th2-related genes such as IL-12, Tbx21, IL-4, and IL-13 [62]. It is important to note that several genes that were associated previously with cerebrovascular function and ischemic brain injury, including ACE and EDN1, were downregulated after DR $\alpha 1-m M O G-35-55$ treatment compared to vehicle treatment.

\section{Permanent distal middle cerebral artery occlusion (dMCAO)}

Post-stroke inflammation includes a rapid activation of microglia followed by the infiltration of peripheral inflammatory cells, including neutrophils, T cells, B cells, and macrophages [64-67]. The influx of these immune cells is known to exacerbate brain injury and deteriorate stroke outcomes $[68,69]$. Therefore, reducing the brain infiltration of peripheral immune cells and reducing cerebral inflammation after stroke may represent effective therapeutic strategies [70]. Since many cases of stroke in humans are non-reperfused, we tested the effect of DR $\alpha 1-M O G-35-55$ in a permanent distal MCAO model of stroke [71].

\section{DRa1-mMOG-35-55 treatment significantly reduces infarct size at 4 days after $d M C A O$}

Daily subcutaneous treatment with DR $\alpha 1$-mMOG-35-55 for four consecutive days significantly reduced the infarct volume 4 days after the onset of dMCAO as compared with vehicle-treated mice (Fig. 4a; $p<0.05$ ).

\section{DRa1-MOG-35-55 treatment inhibits influx of $T$ lymphocytes into brain after $\triangle M C A O$}

We then evaluated the effects of DRo1-mMOG-35-55 treatment on immune cell infiltration into the ischemic brain 4 days after dMCAO. The brain tissue was collected from the ipsilateral brain, and single-cell suspension was prepared for FACS analysis. The results showed that DR $\alpha 1-m M O G-35-55$ treatment markedly decreased the number of $\mathrm{CD}^{+} \mathrm{CD} 4^{+} \mathrm{T}$ cells (Fig. 4b) and $\mathrm{CD}^{+} \mathrm{CD}^{+} \mathrm{T}$ cells (Fig. 4c) in the ischemic hemisphere compared to those of the vehicle-treated mice.

\section{DRa1-mMOG-35-55 treatment enhances polarization of anti-inflammatory microglia/macrophages in the ischemic brain after $A M C A O$}

It has been demonstrated that DR $\alpha 1-m M O G-35-55$ treatment can reduce the number of activated macrophages in the transient MCAO model [72]. Therefore, we sought to assess whether DR $\alpha$-mMOG-35-55 treatment could also reduce the number of activated microglia/macrophage in the distal permanent model of stroke. $\mathrm{CD} 11 \mathrm{~b}^{+} \mathrm{CD} 45^{\text {int }}$ microglia and $\mathrm{CD} 11 \mathrm{~b}^{+} \mathrm{CD} 45^{\text {high }}$ macrophages were distinguished by flow cytometry. The total number of macrophages and microglia showed no difference between DR 1 -mMOG-35-55-treated and vehicle-treated mice at day 4 after dMCAO. Immunofluorescent staining of $\mathrm{F} 4 / 80$ confirmed comparable 


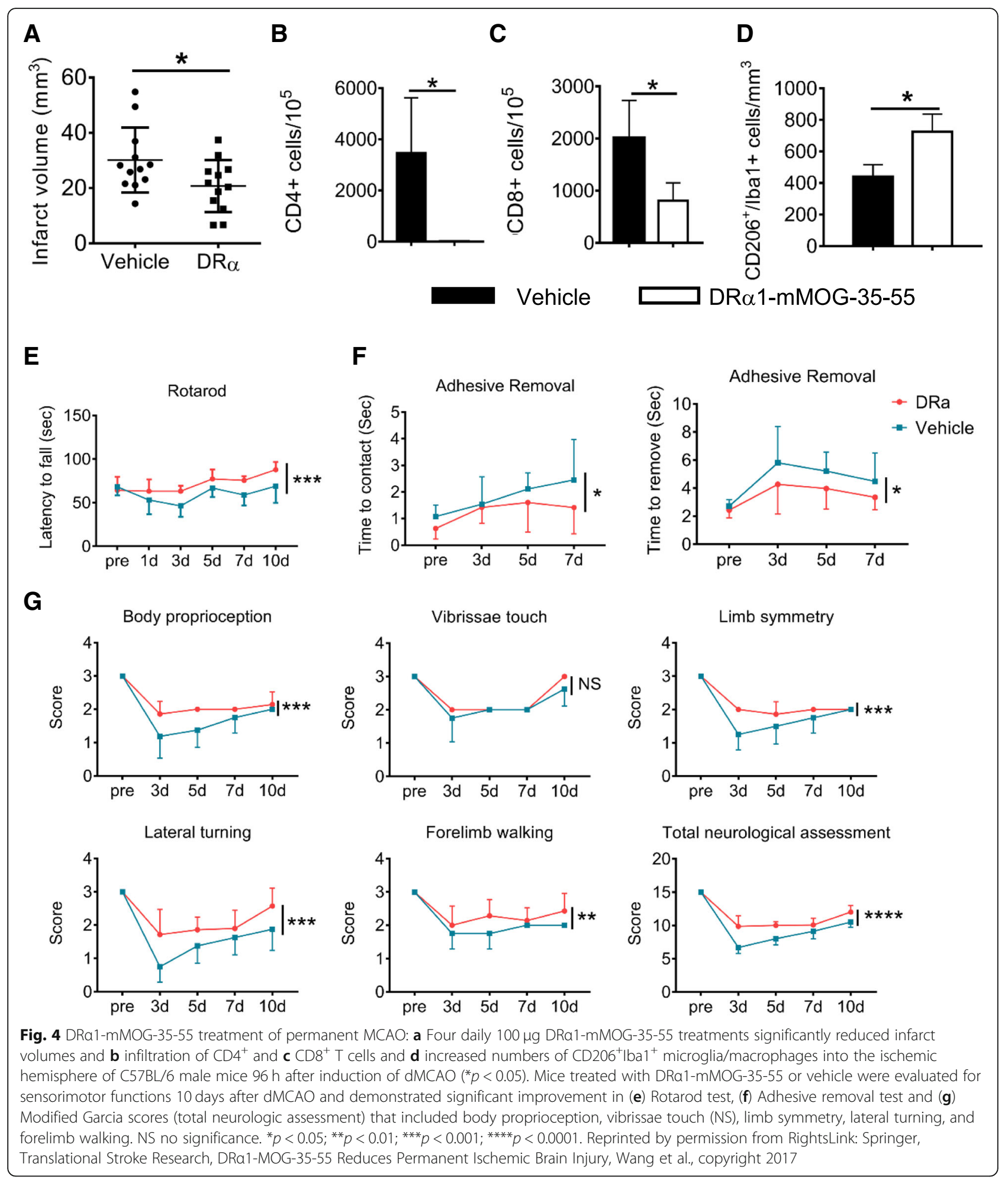

numbers of $\mathrm{F} 4 / 80+$ macrophages in the ischemic areas in DRo1-mMOG-35-55-treated and vehicle-treated mice. Interestingly, the expression of the M2-like marker, CD206, was significantly upregulated in $\mathrm{Iba}^{+}$ microglia/macrophage in DR 1 -mMOG-35-55-treated mice as compared to vehicle-treated controls (Fig. 4d). These results suggest that although DR $\alpha 1$-mMOG-35-55 does not reduce the number of activated microglia/ macrophage after $\mathrm{dMCAO}$, it can shift microglia/macrophage toward a beneficial anti-inflammatory phenotype. 
DRa1-mMOG-35-55 treatment reduces the gene expression of inflammatory cytokines in the ischemic brain after distal MCAO

In order to evaluate the effect of DR $\alpha 1-m M O G-35-55$ treatment on cerebral inflammation after $\mathrm{dMCAO}$, we measured the mRNA expression of several pro-inflammatory cytokines in the ischemic brain using RT-PCR at 4 days after dMCAO. DR $\alpha 1-$ mMOG-35-55 treatment significantly reduced the expression of IL- $1 \alpha$ and IL-17 in ipsilateral hemispheres compared to that of vehicle-treated mice, although the expression of TNF- $\alpha$ or IFN- $\gamma$ was not statistically different.

\section{Methamphetamine addiction}

Methamphetamine use causes long-term neuropsychiatric impairments that make addiction to this drug extremely challenging to treat $[73,74]$. Relapse rates following current methamphetamine abuse treatments are very high $(\sim 40-60 \%)$ [75], and the neuropsychiatric impairments (e.g., cognitive deficits, mood disorders) that arise and persist during remission from methamphetamine addiction likely contribute to these high relapse rates [76]. Pharmacotherapeutic development of medications to treat addiction has focused on neurotransmitter systems with only limited success, and there are no Food and Drug Administration-approved pharmacotherapies for methamphetamine addiction. Methamphetamine dependence is associated with long-term structural damage to regions of the brain that control cognitive and behavioral function [77-79]. A growing literature shows that methamphetamine alters peripheral and central immune functions and immune factors such as cytokines, chemokines, and adhesion molecules play a role in the development and persistence of methamphetamine-induced neuronal injury and neuropsychiatric impairments [80, 81].

These observations that parallel immune-mediated damage in other conditions marked by CNS damage discussed in this review provided a strong rationale for use of RTL constructs for treatment of methamphetamine addiction. We thus evaluated the efficacy of the RTL551 construct (I-A $\mathrm{A}^{\mathrm{b}} \beta 1 \alpha 1$ domains linked to mMOG-35-55), in treating learning and memory impairments induced by repeated methamphetamine exposure. C57BL/6 mice were exposed to two different methamphetamine treatment regimens (using repeated doses of $4 \mathrm{mg} / \mathrm{kg}$ or $10 \mathrm{mg} / \mathrm{kg}$, s.c.). Cognitive performance was assessed using the Morris water maze and CNS cytokine levels were measured by multiplex assay. Immunotherapy with RTL551 improved the memory impairments induced by repeated methamphetamine exposure in both mouse models of chronic methamphetamine addition. Treatment with RTL551 also attenuated the methamphetamine-induced increases in hypothalamic interleukin-2 (IL-2) levels. Collectively, these initial results indicate that neuroimmune targeted therapies, potentially including DR $\alpha 1-\mathrm{hMOG}-35-55$ constructs, may have potential as treatments for methamphetamine-induced neuropsychiatric impairments [82].

\section{Traumatic brain injury}

Traumatic brain injury (TBI) results in severe neurological impairments without effective treatments. The primary injury occurs upon impact, disrupting the blood-brain barrier and blood vessels that cause brain edema [83]. Inflammation involving migration of activated peripheral immune cells and resident microglia and astrocytes appears to be an important contributor to key pathogenic events that result in secondary brain injury following TBI [83-86] and therefore serves as a promising target for novel anti-inflammatory therapies. As shown above, we have demonstrated the ability of the DR $\alpha$-mMOG-35-55 construct to reduce CNS inflammation and tissue injury in animal models of multiple sclerosis, ischemic injury, and methamphetamine addiction. Thus, we sought to determine if DR 1 -mMOG-35-55 treatment of a fluid percussion injury (FPI) mouse model of TBI could reduce the lesion size and improve disease outcome measures [87].

\section{DRa1-mMOG-35-55 attenuates neurodeficits and lesion volume in FPI mice}

To assess the therapeutic effects of DR $\alpha 1$-mMOG-35-55 after TBI, we measured neurological impairment scores and lesion volumes in mice subjected to FPI. Mice received nine daily s.c. injections of $100 \mu \mathrm{g}$ DR $\alpha$-mMOG-35-55 or vehicle starting immediately after FPI (Fig. 5a) and were assessed intermittently and $24 \mathrm{~h}$ after the final treatment (day 10) using the modified Neurological Severity Score (mNSS) and the Corner Turning test. DR $\alpha 1-m M O G-35-55$ treatment significantly reduced both neurodeficit measures (Fig. 5a) as well as lesion volumes (Fig. $5 \mathrm{~b}$ ) at all time points measured after TBI compared to vehicle controls (Fig. 5c).

\section{DRa1-mMOG-35-55 reduces brain infiltration of CD11 $b^{+}$ cells and their expression of $C D 74$}

To determine whether DR 1 -mMOG-35-55 treatment of brain injury could affect the cell numbers and CD74 expression of $\mathrm{CD}_{11} \mathrm{~b}^{+}$cells in the brain, we assessed numbers of non-activated brain-intrinsic microglia $\left(\mathrm{CD} 11 \mathrm{~b}^{+} \mathrm{CD} 45^{\text {int }}\right)$ and brain-infiltrating macrophages/activated microglia $\left(\mathrm{CD} 11 \mathrm{~b}^{+} \mathrm{CD} 45^{\mathrm{hi}}\right)$ after TBI. We found that DR 1 1-mMOG-35-55 treatment significantly reduced the total number of brain-infiltrating cells $(p=$ 0.01) (Fig. 5d), with predominant effects on CD $11 b^{+} \mathrm{CD} 45^{\text {hi }}$ macrophages/activated microglia (Fig. 5e) 


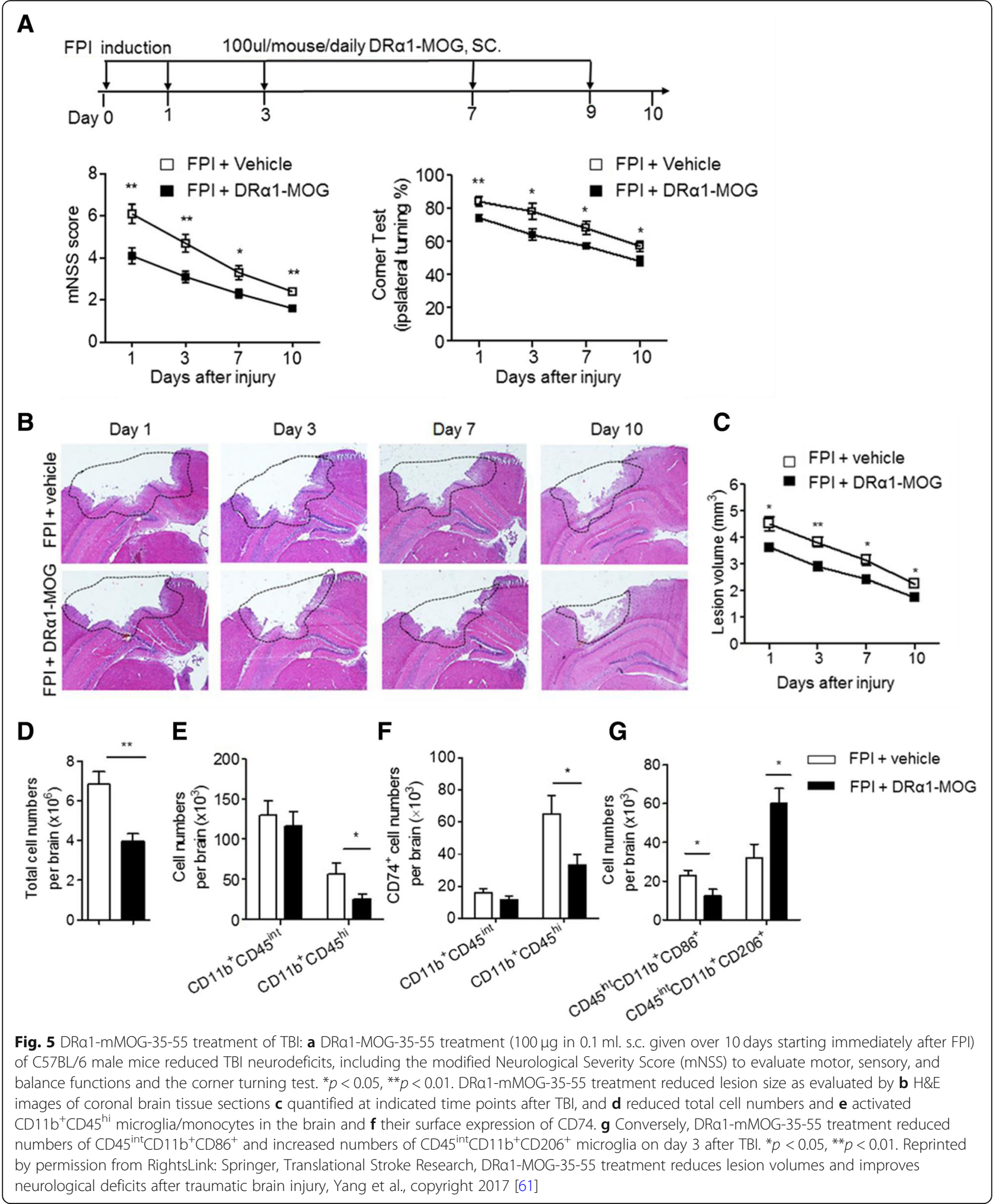

that expressed CD74 ( $p=0.03)$ (Fig. 5f). In contrast, no changes were observed in total numbers or CD74 expression of non-activated $\mathrm{CD} 11 \mathrm{~b}^{+} \mathrm{CD} 45^{\text {int }}$ microglia after treatment with DR $\alpha 1-m M O G-35-55 \quad(p=0.12)$. These results thus demonstrate that treatment with the DR $\alpha 1-m M O G-35-55$ construct can reduce the infiltration and local activation of $\mathrm{CD} 11 \mathrm{~b}^{+} \mathrm{CD} 45^{\text {hi }}$ cells in the injured brain and their expression of CD74 after TBI. 
CD86 and CD206 are two markers routinely used to respectively characterize the pro-inflammatory versus anti-inflammatory phenotypes of $\mathrm{CD} 11 \mathrm{~b}^{+} \mathrm{CD} 45^{\text {int }}$ cells. We therefore determined the expression of CD86 and CD206 by brain-infiltrating $\mathrm{CD} 11 \mathrm{~b}^{+} \mathrm{CD} 45^{\text {int }}$ cells. The results clearly demonstrated a reduction of CD86-expressing inflammatory $\mathrm{CD} 11 \mathrm{~b}^{+} \mathrm{CD} 45^{\text {int }}$ cells $(p$ $=0.03)$ and an increase of anti-inflammatory CD206-expressing $\mathrm{CD} 11 \mathrm{~b}^{+} \mathrm{CD} 45^{\text {int }}$ cells after treatment with DR $\alpha 1$-mMOG-35-55 ( $p=0.02)$ (Fig. 5g).

This study provides the first evidence that DR 1 1-MOG-35-55 treatment improves the outcome of TBI. Our results demonstrate that daily s.c. administration of DR $\alpha 1-M O G-35-55$ can significantly enhance functional outcomes, reduce brain lesion size, block infiltration of $\mathrm{CD}_{11 \mathrm{~b}^{+}}$cells into the injured brain, and promote an anti-inflammatory phenotype in activated $\mathrm{CD} 11 \mathrm{~b}^{+} \mathrm{CD} 45^{\mathrm{hi}}$ cells that infiltrate from the periphery or that result from local activation of resident $\mathrm{CD}_{11} \mathrm{~b}^{+} \mathrm{CD} 45^{\mathrm{int}}$ microglia after TBI [87]. These anti-inflammatory changes observed in the injured brain were in stark contrast with increased numbers of activated monocytes in the blood that were inhibited from crossing the blood-brain barrier into the CNS and the lack of any demonstrable changes in the spleen (not shown).

\section{DRhQ as the next generation anti-inflammatory drug for CNS pathological conditions}

An analysis of the alignment of several human Class II $\alpha 1$ domains revealed a unique characteristic of the DR $\alpha 1$ domain not shared with other human or mouse class II [88]. This unique feature shows a glutamine (Q) residue at position 18 in most of the sequences used in the alignment. The DR $\alpha 1$ domain stands apart from the other sequences, however, with a leucine $(\mathrm{L})$ at position 18. It is noteworthy that along with the other peptide-presenting Class II domains, this Q18 residue is also conserved among the non-antigen presenting proteins DM $\alpha 1$ and DO $\alpha 1$. In all the analyzed Class II $\alpha 1$

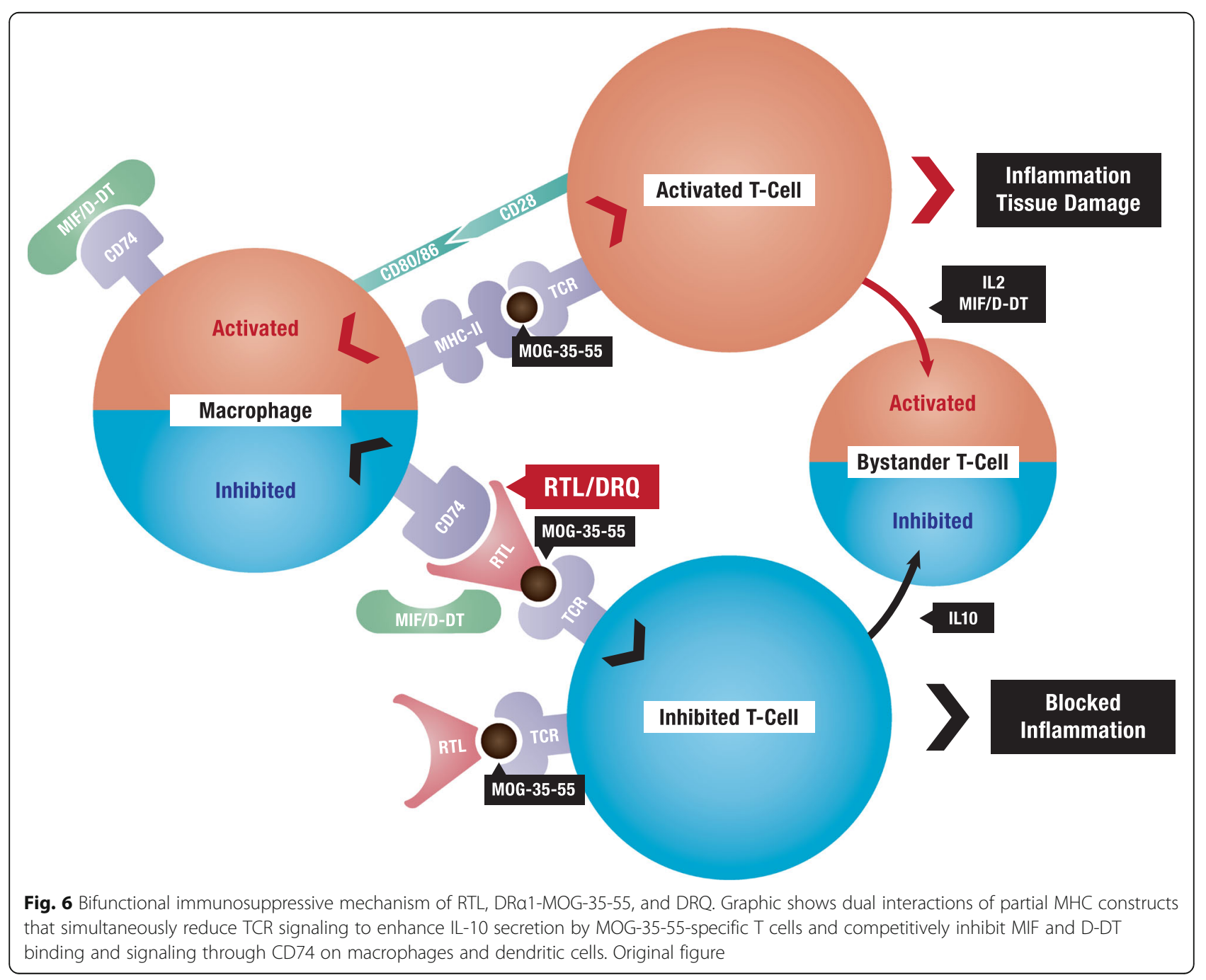


domain primary sequences and the crystal structures stored in the Protein Data Blank (PDB), this region localizes in the loop between $\beta$-strand 1 and $\beta$-strand 2 at the $\mathrm{N}$-terminus of the polypeptide pointing outwards of the bulk of the molecule. Based on this information, we introduced an amino acid substitution of glutamine for leucine at position 18 of the DR $\alpha 1$ domain (position 50 of the DR $\alpha 1$-hMOG-35-55 construct) termed DRhQ that was found to enhance the binding affinity of the construct for CD74 by $8-10$-fold. This substitution did not affect the structure of the molecule as evaluated by circular dichroism and conformational antibody probing. With regard to potential clinical application, the increased binding affinity translated into a commensurate ability of DRhQ to competitively inhibit MIF binding to its cognate CD74 receptor and significantly enhanced the ability of the construct to treat ongoing clinical signs of severe EAE. Moreover, DRhQ treatment of WT C57BL/6 mice with EAE reduced the increased pERK1/2 phosphorylation levels in vitro in splenocytes to a background level. These data suggest that binding affinity for CD74 could serve as an in vitro indicator of DRhQ potency and reduced pERK levels in peripheral blood mononuclear cells after injection, an in vivo indicator of DRhQ biological activity. These measures of activity will be of value when seeking FDA approval for use of the DRhQ construct as an Investigational New Drug in human clinical trials.

\section{Summary and conclusions}

DR 1 1-mMOG-35-55 treatment of EAE, ischemic injury, methamphetamine addiction and TBI results in highly significant clinical and histological improvement as well as increased neurological functionality. This is likely due to the striking ability of DR $\alpha 1-\mathrm{mMOG}-35-55$ and DRhQ to modulate common inflammatory pathways (illustrated in Fig. 6) and enhance remyelination and neuroprotection through dual regulatory mechanisms. This review provides evidence from several CNS inflammatory conditions showing that the DR $\alpha 1$ construct can strongly inhibit the activation and recruitment of brain-infiltrating $\mathrm{T}$ cells and $\mathrm{CD} 11 \mathrm{~b}^{+} \mathrm{CD} 45^{\text {hi }}$ myeloid cells that have increased expression of CD74 subsequent to CNS damage. DR $\alpha 1-m M O G-35-55$ also reduced expression of the co-stimulatory $\mathrm{CD} 86$ marker on $\mathrm{CD} 11 \mathrm{~b}^{+} \mathrm{CD} 45^{\text {hi }}$ cells but enhanced expression of the anti-inflammatory

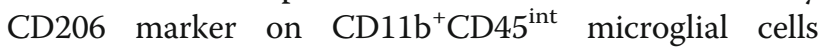
within the CNS. Establishing the common therapeutic activity of DR 1 -mMOG-35-55 for these various CNS conditions in mouse models portends well for successful treatment of these and other CNS conditions by our more potent next generation DRhQ construct designed for human use.

\begin{abstract}
Abbreviations
(h)MOG-35-55: Human; (m)MOG-35-55: Mouse; (p)ERK1/2: Phosphorylated; APC: Antigen presenting cells; CNS: Central nervous system; D-DT=MIF-2: DDopachrome tautomerase; dMCA: Permanent distal middle cerebral artery occlusion; EAE: Experimental autoimmune encephalomyelitis;

ERK: Extracellular-regulated kinase; ERa or ERKO: Estrogen receptor alpha; ERß or BERKO: Estrogen receptor beta; FACS: Fluorescence-activated cell sorting; FPI: Fluid percussion injury; GFP: Green fluorescent protein; HDAC5: Histone deacetylase 5; IL-2: Interleukin-2; L: Leucine; MBP: Myelin basic protein; MCAO: Middle cerebral artery occlusion; MIF: Macrophage migration inhibitory factor; mNSS: Modified neurological severity score; MOG: Myelin oligodendrocyte glycoprotein; MS: Multiple sclerosis; MYOC: Myocilin; OVX: Ovariectomized; PDB: Protein Data Blank; PDPK-1: 3-Phosphoinositidedependent protein kinase 1; PLP: Proteolipid protein; PMHC: Partial major histocompatibility complex class II constructs; PSAP: PROSAPOSIN; Q: Glutamine; RTL: Recombinant T cell receptor ligand; SAR: Structure activity relationship; STAIR: Stroke Academic Industry Roundtable; TBI: Traumatic brain injury; TCR: T cell receptor; tPA: Tissue plasminogen activator; WT: Wild-type
\end{abstract}

\section{Acknowledgements}

The authors wish to thank Gail Kent and Grant Gerstner for help in preparing and submitting the manuscript.

\section{Funding}

This work was funded by the National Institute of Allergy and Infectious Diseases award R42Al122574 (AAV), National Institute Of Neurological Disorders And Stroke R01NS080890 (HO), and the Department of Veterans Affairs, Veterans Health Administration, Office of Research and Development, Biomedical Laboratory Research and Development Merit Review Award 2101 BX000226 and Senior Research Career Scientist Award 1IK6BX004209 (AAV). The contents do not represent the views of the Department of Veterans Affairs or the US Government.

\section{Availability of data and materials}

The datasets used and/or analyzed during the current study are available from the corresponding author on reasonable request.

\section{Authors' contributions}

The manuscript was written by AAV and $\mathrm{HO}$; this was edited and reviewed by GB and RMR. All authors read and approved the final manuscript.

\section{Ethics approval and consent to participate}

Not applicable to this review specifically.

\section{Consent for publication}

Not applicable to this review specifically.

\section{Competing interests}

Drs. Vandenbark, Offner, Benedek, Meza-Romero, and OHSU have a significant financial interest in Artielle ImmunoTherapeutics, Inc., a company that may have a commercial interest in the results of this research and technology. This potential conflict of interest has been reviewed and managed by the OHSU and VA Portland Health Care System Conflict of Interest in Research Committees.

\section{Publisher's Note}

Springer Nature remains neutral with regard to jurisdictional claims in published maps and institutional affiliations.

\footnotetext{
Author details

${ }^{1}$ Neuroimmunology Research, R\&D-31, VA Portland Health Care System, 3710 SW U.S. Veterans Hospital Rd., Portland, OR 97239, USA. ${ }^{2}$ Department of Neurology, Oregon Health \& Science University, 3181 SW Sam Jackson Park Rd, Portland, OR 97239, USA. ${ }^{3}$ Department of Molecular Microbiology \& Immunology, Oregon Health \& Science University, 3181 SW Sam Jackson Park Rd, Portland, OR 97239, USA. ${ }^{4}$ Present Address: Tissue Typing and Immunogenetics Laboratory, Hadassah Medical Center, Jerusalem, Israel. ${ }^{5}$ Department of Anesthesiology and Perioperative Medicine, Oregon Health \& Science University, 3181 SW Sam Jackson Park Rd, Portland, OR 97239, USA.
} 
Received: 17 December 2018 Accepted: 27 December 2018 Published online: 23 January 2019

\section{References}

1. Burrows GG. Systemic immunomodulation of autoimmune disease using MHC-derived recombinant TCR ligands. Curr Drug Targets Inflamm Allergy. 2005:4:185-93.

2. Burrows GG, Chang JW, Bachinger HP, Bourdette DN, Offner H, Vandenbark AA. Design, engineering and production of functional single-chain $T$ cell receptor ligands. Protein Eng. 1999;12:771-8.

3. Offner $H$, Sinha S, Wang C, Burrows GG, Vandenbark AA. Recombinant T cell receptor ligands: immunomodulatory, neuroprotective and neuroregenerative effects suggest application as therapy for multiple sclerosis. Rev Neurosci. 2008;19:327-39.

4. Burrows GG, Adlard KL, Bebo BF Jr, Chang JW, Tenditnyy K, Vandenbark AA, Offner $\mathrm{H}$. Regulation of encephalitogenic T cells with recombinant TCR ligands. J Immunol. 2000;164:6366-71.

5. Burrows GG, Chou YK, Wang C, Chang JW, Finn TP, Culbertson NE, Kim J, Bourdette DN, Lewinsohn DA, Lewinsohn DM, et al. Rudimentary TCR signaling triggers default IL-10 secretion by human Th1 cells. J Immunol. 2001;167:4386-95.

6. McMahan RH, Watson L, Meza-Romero R, Burrows GG, Bourdette DN, Buenafe AC. Production, characterization, and immunogenicity of a soluble rat single chain $T$ cell receptor specific for an encephalitogenic peptide. J Biol Chem. 2003;278:30961-70.

7. Huan J, Subramanian S, Jones R, Rich C, Link J, Mooney J, Bourdette DN, Vandenbark AA, Burrows GG, Offner H. Monomeric recombinant TCR ligand reduces relapse rate and severity of experimental autoimmune encephalomyelitis in SJL/J mice through cytokine switch. J Immunol. 2004;172:4556-66.

8. Sinha S, Subramanian S, Miller L, Proctor TM, Roberts C, Burrows GG, Vandenbark AA, Offner $\mathrm{H}$. Cytokine switch and bystander suppression of autoimmune responses to multiple antigens in experimental autoimmune encephalomyelitis by a single recombinant T-cell receptor ligand. J Neurosci. 2009;29:3816-23.

9. Offner H, Subramanian S, Wang C, Afentoulis M, Vandenbark AA, Huan J, Burrows GG. Treatment of passive experimental autoimmune encephalomyelitis in SJL mice with a recombinant TCR ligand induces IL-13 and prevents axonal injury. J Immunol. 2005;175:4103-11.

10. Wang C, Gold BG, Kaler LJ, Yu X, Afentoulis ME, Burrows GG, Vandenbark AA, Bourdette DN, Offner H. Antigen-specific therapy promotes repair of myelin and axonal damage in established EAE. $J$ Neurochem. 2006;98:1817-27.

11. Sinha S, Subramanian S, Proctor TM, Kaler $\sqcup$, Grafe M, Dahan R, Huan J, Vandenbark AA, Burrows GG, Offner H. A promising therapeutic approach for multiple sclerosis: recombinant T-cell receptor ligands modulate experimental autoimmune encephalomyelitis by reducing interleukin-17 production and inhibiting migration of encephalitogenic cells into the CNS. J Neurosci. 2007;27: 12531-9.

12. Chang JW, Mechling DE, Bachinger HP, Burrows GG. Design, engineering, and production of human recombinant $t$ cell receptor ligands derived from human leukocyte antigen DR2. J Biol Chem. 2001;276:24170-6.

13. Huan JY, Meza-Romero R, Mooney JL, Chou YK, Edwards DM, Rich C, Link JM, Vandenbark AA, Bourdette DN, Bachinger HP, Burrows GG. Rationally designed mutations convert complexes of human recombinant $\mathrm{T}$ cell receptor ligands into monomers that retain biological activity. J Chem Technol Biotechnol. 2005;80:2-12

14. Chou YK, Culbertson N, Rich C, LaTocha D, Buenafe AC, Huan J, Link J, Wands JM, Born WK, Offner $\mathrm{H}$, et al. T-cell hybridoma specific for myelin oligodendrocyte glycoprotein-35-55 peptide produced from HLADRB1*1501-transgenic mice. J Neurosci Res. 2004;77:670-80.

15. Vandenbark AA, Rich C, Mooney J, Zamora A, Wang C, Huan J, Fugger L,

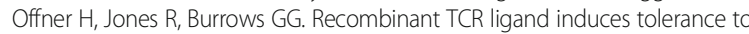
myelin oligodendrocyte glycoprotein 35-55 peptide and reverses clinical and histological signs of chronic experimental autoimmune encephalomyelitis in HLA-DR2 transgenic mice. J Immunol. 2003;171:127-33.

16. Link JM, Rich CM, Korat $M$, Burrows GG, Offner $H$, Vandenbark AA. Monomeric DR2/MOG-35-55 recombinant TCR ligand treats relapses of experimental encephalomyelitis in DR2 transgenic mice. Clin Immunol. 2007;123:95-104.

17. Vandenbark AA, Meza-Romero R, Benedek G, Andrew S, Huan J, Chou YK, Buenafe AC, Dahan R, Reiter Y, Mooney JL, et al. A novel regulatory pathway for autoimmune disease: binding of partial MHC class II constructs to monocytes reduces CD74 expression and induces both specific and bystander T-cell tolerance. J Autoimmun. 2013;40:96-110.

18. Wang C, Mooney JL, Meza-Romero R, Chou YK, Huan J, Vandenbark AA, Offner $H$, Burrows GG. Recombinant TCR ligand induces early TCR signaling and a unique pattern of downstream activation. J Immunol. 2003;171:1934-40.

19. Offner H, Sinha S, Burrows GG, Ferro AJ, Vandenbark AA. RTL therapy for multiple sclerosis: a phase I clinical study. J Neuroimmunol. 2011;231:7-14.

20. Yadav V, Bourdette DN, Bowen JD, Lynch SG, Mattson D, Preiningerova J, Bever CT Jr, Simon J, Goldstein A, Burrows GG, et al. Recombinant T-cell receptor ligand (RTL) for treatment of multiple sclerosis: a double-blind, placebo-controlled, phase 1, dose-escalation study. Autoimmune Dis. 2012; 2012:954739.

21. Sinha S, Miller L, Subramanian S, McCarty OJ, Proctor T, Meza-Romero R, Huan J, Burrows GG, Vandenbark AA, Offner H. Binding of recombinant T cell receptor ligands (RTL) to antigen presenting cells prevents upregulation of CD11b and inhibits T cell activation and transfer of experimental autoimmune encephalomyelitis. J Neuroimmunol. 2010;225:52-61.

22. Meza-Romero R, Benedek G, Yu X, Mooney JL, Dahan R, Duvshani N, Bucala R, Offner H, Reiter Y, Burrows GG, Vandenbark AA. HLA-DRalpha1 constructs block CD74 expression and MIF effects in experimental autoimmune encephalomyelitis. J Immunol. 2014;192:4164-73.

23. Sospedra M, Martin R. Immunology of multiple sclerosis. Annu Rev Immunol. 2005;23:683-747

24. Steinman L. Multiple sclerosis: a two-stage disease. Nat Immunol. 2001;2:762-4.

25. Frohman EM, Racke MK, Raine CS. Multiple sclerosis--the plaque and its pathogenesis. N Engl J Med. 2006;354:942-55.

26. Herrero-Herranz E, Pardo LA, Gold R, Linker RA. Pattern of axonal injury in murine myelin oligodendrocyte glycoprotein induced experimental autoimmune encephalomyelitis: implications for multiple sclerosis. Neurobiol Dis. 2008;30:162-73.

27. Steinman L. Multiple sclerosis: a coordinated immunological attack against myelin in the central nervous system. Cell. 1996;85:299-302.

28. Benedek G, Meza-Romero R, Jordan K, Keenlyside L, Offner $H$, Vandenbark AA. HLA-DRalpha1-mMOG-35-55 treatment of experimental autoimmune encephalomyelitis reduces CNS inflammation, enhances M2 macrophage frequency, and promotes neuroprotection. J Neuroinflammation. 2015;12:123.

29. Jiang Z, Jiang JX, Zhang GX. Macrophages: a double-edged sword in experimental autoimmune encephalomyelitis. Immunol Lett. 2014;160: $17-22$.

30. Mikita J, Dubourdieu-Cassagno N, Deloire MS, Vekris A, Biran M, Raffard G, Brochet B, Canron MH, Franconi JM, Boiziau C, Petry KG. Altered M1/M2 activation patterns of monocytes in severe relapsing experimental rat model of multiple sclerosis. Amelioration of clinical status by M2 activated monocyte administration. Mult Scler. 2011;17:2-15.

31. Miron VE, Franklin RJ. Macrophages and CNS remyelination. J Neurochem. 2014;130:165-71.

32. D'Arca D, Zhao X, Xu W, Ramirez-Martinez NC, lavarone A, Lasorella A. Huwe1 ubiquitin ligase is essential to synchronize neuronal and glial differentiation in the developing cerebellum. Proc Natl Acad Sci U S A. 2010;107:5875-80

33. Kharebava G, Makonchuk D, Kalita KB, Zheng JJ, Hetman M. Requirement of 3-phosphoinositide-dependent protein kinase-1 for BDNF-mediated neuronal survival. J Neurosci. 2008;28:11409-20.

34. Kwon HS, Nakaya N, Abu-Asab M, Kim HS, Tomarev SI. Myocilin is involved in NgR1/Lingo-1-mediated oligodendrocyte differentiation and myelination of the optic nerve. J Neurosci. 2014;34:5539-51.

35. Meyer RC, Giddens MM, Coleman BM, Hall RA. The protective role of prosaposin and its receptors in the nervous system. Brain Res. 2014; 1585:1-12.

36. Zhou J, Liu Q, Mao M, Tong Y. Huwe1 as a therapeutic target for neural injury. Genet Mol Res. 2014;13:4320-5.

37. Zurashvili T, Cordon-Barris L, Ruiz-Babot G, Zhou X, Lizcano JM, Gomez N, Gimenez-Llort L, Bayascas JR. Interaction of PDK1 with phosphoinositides is essential for neuronal differentiation but dispensable for neuronal survival. Mol Cell Biol. 2013;33:1027-40.

38. Cho Y, Cavalli V. HDAC5 is a novel injury-regulated tubulin deacetylase controlling axon regeneration. EMBO J. 2012;31:3063-78.

39. Cho Y, Sloutsky R, Naegle KM, Cavalli V. Injury-induced HDAC5 nuclear export is essential for axon regeneration. Cell. 2013;155:894-908. 
40. Benedek G, Chaudhary P, Meza-Romero R, Calkins E, Kent G, Offner H, Bourdette D, Vandenbark AA. Sex-dependent treatment of chronic EAE with partial MHC class II constructs. J Neuroinflammation. 2017;14:100.

41. Kipp M, Amor S, Krauth R, Beyer C. Multiple sclerosis: neuroprotective alliance of estrogen-progesterone and gender. Front Neuroendocrinol. 2012; 33:1-16.

42. Kovats $S$. Estrogen receptors regulate innate immune cells and signaling pathways. Cell Immunol. 2015;294:63-9.

43. Polanczyk MJ, Hopke C, Vandenbark AA, Offner H. Estrogen-mediated immunomodulation involves reduced activation of effector $T$ cells, potentiation of Treg cells, and enhanced expression of the PD-1 costimulatory pathway. J Neurosci Res. 2006;84:370-8.

44. Donnan GA, Fisher M, Macleod M, Davis SM. Stroke. Lancet. 2008;371:1612-23.

45. Lindsay P, Furie KL, Davis SM, Donnan GA, Norrving B. World stroke organization global stroke services guidelines and action plan. Int I Stroke 2014;9 Suppl A100:4-13.

46. Ovbiagele B, Goldstein LB, Higashida RT, Howard VJ, Johnston SC, Khavjou OA, Lackland DT, Lichtman JH, Mohl S, Sacco RL, et al. Forecasting the future of stroke in the United States: a policy statement from the American Heart Association and American Stroke Association. Stroke. 2013;44:2361-75.

47. Campanella M, Sciorati C, Tarozzo G, Beltramo M. Flow cytometric analysis of inflammatory cells in ischemic rat brain. Stroke. 2002;33:586-92.

48. Chamorro A, Meisel A, Planas AM, Urra X, van de Beek D, Veltkamp R. The immunology of acute stroke. Nat Rev Neurol. 2012;8:401-10.

49. Offner $H$, Subramanian S, Parker SM, Afentoulis ME, Vandenbark AA, Hurn PD. Experimental stroke induces massive, rapid activation of the peripheral immune system. J Cereb Blood Flow Metab. 2006;26:654-65.

50. Pennypacker KR, Offner $\mathrm{H}$. The role of the spleen in ischemic stroke. J Cereb Blood Flow Metab. 2015;35:186-7.

51. Urra X, Cervera A, Obach V, Climent N, Planas AM, Chamorro A. Monocytes are major players in the prognosis and risk of infection after acute stroke. Stroke. 2009:40:1262-8.

52. Elkind MS, Cheng J, Rundek T, Boden-Albala B, Sacco RL. Leukocyte count predicts outcome after ischemic stroke: the Northern Manhattan Stroke Study. J Stroke Cerebrovasc Dis. 2004;13:220-7

53. Offner $\mathrm{H}$, Subramanian S, Parker SM, Wang C, Afentoulis ME, Lewis A, Vandenbark AA, Hurn PD. Splenic atrophy in experimental stroke is accompanied by increased regulatory $T$ cells and circulating macrophages. J Immunol. 2006;176:6523-31.

54. Offner $H$, Vandenbark AA, Hurn PD. Effect of experimental stroke on peripheral immunity: CNS ischemia induces profound immunosuppression. Neuroscience. 2009;158:1098-111.

55. Seifert HA, Hall AA, Chapman CB, Collier LA, Willing AE, Pennypacker KR. A transient decrease in spleen size following stroke corresponds to splenocyte release into systemic circulation. J Neurolmmune Pharmacol. 2012;7:1017-24.

56. Ren $X$, Akiyoshi $K$, Grafe MR, Vandenbark AA, Hurn PD, Herson PS, Offner $H$ Myelin specific cells infiltrate MCAO lesions and exacerbate stroke severity. Metab Brain Dis. 2012;27:7-15.

57. Gordon S. Alternative activation of macrophages. Nat Rev Immunol. 2003;3: 23-35.

58. Albers GW, Bates VE, Clark WM, Bell R, Verro P, Hamilton SA. Intravenous tissue-type plasminogen activator for treatment of acute stroke: the Standard Treatment with Alteplase to Reverse Stroke (STARS) study. JAMA 2000;283:1145-50

59. Benedek G, Vandenbark AA, Alkayed NJ, Offner H. Partial MHC class II constructs as novel immunomodulatory therapy for stroke. Neurochem Int. 2017:107:138-47

60. Bix GJ, Fraser JF, Mack WJ, Carmichael ST, Perez-Pinzon M, Offner H, Sansing L, Bosetti F, Ayata C, Pennypacker KR. Uncovering the Rosetta stone: report from the first annual conference on key elements in translating stroke therapeutics from pre-clinical to clinical. Transl Stroke Res. 2018;9:258-66.

61. Yang L, Kong Y, Ren H, Li M, Wei CJ, Shi E, Jin WN, Hao J, Vandenbark AA Offner H. Upregulation of CD74 and its potential association with disease severity in subjects with ischemic stroke. Neurochem Int. 2017;107:148-55.

62. Benedek G, Meza-Romero R, Andrew S, Leng L, Burrows GG, Bourdette D, Offner $H$, Bucala $R$, Vandenbark AA. Partial MHC class II constructs inhibit MIF/CD74 binding and downstream effects. Eur J Immunol. 2013; 43:1309-21.

63. Pan J, Palmateer J, Schallert T, Hart M, Pandya A, Vandenbark AA, Offner $H$, Hurn PD. Novel humanized recombinant T cell receptor ligands protect the female brain after experimental stroke. Transl Stroke Res. 2014;5:577-85.
64. Brown CM, Bushnell CD, Samsa GP, Goldstein LB, Colton CA. Chronic systemic immune dysfunction in African-Americans with small vessel-type ischemic stroke. Transl Stroke Res. 2015;6:430-6.

65. Chen S, Yang Q, Chen G, Zhang JH. An update on inflammation in the acute phase of intracerebral hemorrhage. Transl Stroke Res. 2015;6:4-8.

66. An C, Shi Y, Li P, Hu X, Gan Y, Stetler RA, Leak RK, Gao Y, Sun BL, Zheng P, Chen J. Molecular dialogs between the ischemic brain and the peripheral immune system: dualistic roles in injury and repair. Prog Neurobiol. 2014; 115:6-24

67. Liesz A, Kleinschnitz C. Regulatory T cells in post-stroke immune homeostasis. Transl Stroke Res. 2016;7:313-21.

68. Atangana E, Schneider UC, Blecharz K, Magrini S, Wagner J, Nieminen-Kelha M, Kremenetskaia I, Heppner FL, Engelhardt B, Vajkoczy P. Intravascular inflammation triggers intracerebral activated microglia and contributes to secondary brain injury after experimental subarachnoid hemorrhage (eSAH). Transl Stroke Res. 2017:8:144-56.

69. Petrone AB, O'Connell GC, Regier MD, Chantler PD, Simpkins JW, Barr TL. The role of arginase 1 in post-stroke immunosuppression and ischemic stroke severity. Transl Stroke Res. 2016;7:103-10.

70. Yang B, Parsha K, Schaar K, Xi X, Aronowski J, Savitz SI. Various cell populations within the mononuclear fraction of bone marrow contribute to the beneficial effects of autologous bone marrow cell therapy in a rodent stroke model. Transl Stroke Res. 2016;7:322-30.

71. Wang J, Ye Q, Xu J, Benedek G, Zhang H, Yang Y, Liu H, Meza-Romero R, Vandenbark AA, Offner H, Gao Y. DRalpha1-MOG-35-55 Reduces Permanent Ischemic Brain Injury. Transl Stroke Res. 2017;8:284-93.

72. Benedek G, Zhu W, Libal N, Casper A, Yu X, Meza-Romero R, Vandenbark AA, Alkayed NJ, Offner H. A novel HLA-DRalpha1-MOG-35-55 construct treats experimental stroke. Metab Brain Dis. 2014;29:37-45.

73. Scott JC, Woods SP, Matt GE, Meyer RA, Heaton RK, Atkinson JH, Grant I. Neurocognitive effects of methamphetamine: a critical review and metaanalysis. Neuropsychol Rev. 2007;17:275-97.

74. Hoffman WF, Moore M, Templin R, MCFarland B, Hitzemann RJ, Mitchell SH. Neuropsychological function and delay discounting in methamphetaminedependent individuals. Psychopharmacology. 2006;188:162-70.

75. McLellan AT, Lewis DC, O'Brien CP, Kleber HD. Drug dependence, a chronic medical illness: implications for treatment, insurance, and outcomes evaluation. JAMA. 2000;284:1689-95.

76. London ED, Simon SL, Berman SM, Mandelkern MA, Lichtman AM, Bramen J, Shinn AK, Miotto K, Learn J, Dong Y, et al. Mood disturbances and regional cerebral metabolic abnormalities in recently abstinent methamphetamine abusers. Arch Gen Psychiatry. 2004;61:73-84.

77. Schwartz DL, Mitchell AD, Lahna DL, Luber HS, Huckans MS, Mitchell SH, Hoffman WF. Global and local morphometric differences in recently abstinent methamphetamine-dependent individuals. Neuroimage. 2010;50: 1392-401.

78. Berman S, O'Neill J, Fears S, Bartzokis G, London ED. Abuse of amphetamines and structural abnormalities in the brain. Ann N Y Acad Sci. 2008;1141:195-220.

79. Hoffman WF, Schwartz DL, Huckans MS, McFarland BH, Meiri G, Stevens AA, Mitchell SH. Cortical activation during delay discounting in abstinent methamphetamine dependent individuals. Psychopharmacology. 2008;201:183-93.

80. Shah A, Silverstein PS, Singh DP, Kumar A. Involvement of metabotropic glutamate receptor 5, AKT/PI3K signaling and NF-kappaB pathway in methamphetamine-mediated increase in IL-6 and IL-8 expression in astrocytes. J Neuroinflammation. 2012;9:52.

81. In SW, Son EW, Rhee DK, Pyo S. Methamphetamine administration produces immunomodulation in mice. J Toxicol Environ Health A. 2005:68:2133-45.

82. Loftis JM, Wilhelm CJ, Vandenbark AA, Huckans M. Partial MHC/ neuroantigen peptide constructs: a potential neuroimmune-based treatment for methamphetamine addiction. PLoS One. 2013;8:e56306.

83. McKee CA, Lukens JR. Emerging roles for the immune system in traumatic brain injury. Front Immunol. 2016;7:556.

84. Kumar A, Loane DJ. Neuroinflammation after traumatic brain injury: opportunities for therapeutic intervention. Brain Behav Immun. 2012;26:1191-201.

85. Raghupathi R. Cell death mechanisms following traumatic brain injury. Brain Pathol. 2004;14:215-22.

86. Ramlackhansingh AF, Brooks DJ, Greenwood RJ, Bose SK, Turkheimer FE, Kinnunen KM, Gentleman S, Heckemann RA, Gunanayagam K, Gelosa G, Sharp DJ. Inflammation after trauma: microglial activation and traumatic brain injury. Ann Neurol. 2011;70:374-83. 
87. Yang L, Liu Z, Ren H, Zhang L, Gao S, Ren L, Chai Z, Meza-Romero R, Benedek G, Vandenbark AA, et al. DRalpha1-MOG-35-55 treatment reduces lesion volumes and improves neurological deficits after traumatic brain injury. Metab Brain Dis. 2017:32:1395-402.

88. Meza-Romero R, Benedek G, Gerstner G, Kent G, Nguyen H, Offner H, Vandenbark AA. Increased CD74 binding and EAE treatment efficacy of a modified DRa1 molecular construct. Metab Brain Dis. 2018; In Press.

Ready to submit your research? Choose BMC and benefit from:

- fast, convenient online submission

- thorough peer review by experienced researchers in your field

- rapid publication on acceptance

- support for research data, including large and complex data types

- gold Open Access which fosters wider collaboration and increased citations

- maximum visibility for your research: over $100 \mathrm{M}$ website views per year

At $\mathrm{BMC}$, research is always in progress.

Learn more biomedcentral.com/submissions 